\title{
Characterization of Failure Surfaces of Epoxy Adhesive Under Varying Quasi- Static Loading Conditions
}

\author{
Hafiz $\mathrm{Ali}^{1}$ and Abdul Khaliq ${ }^{2}$ \\ ${ }^{1}$ Mechanical Engineering Department, Faculty of Engineering, Taif University, Kingdom of Saudi Arabia, \\ ${ }^{2}$ Mechanical Engineering Department, Faculty of Engineering, University of Hail, Hail, Kingdom of \\ Saudi Arabia
}

Epoxy resin thermosetting are used as a structural bonding composite material owing to their extraordinary adhesive properties and durability especially when they are bonded with metals. Such light weight and durable structural materials have emerged an important aerospace material which are being investigated for their failure under varying quasi-static loading conditions. In this study, one of the important epoxy resin adhesive materials named as FM73 was investigated [1]. The FM73 was supplied by Cytec Engineering Materials, United Kingdom.

It is a challenging task to investigate fracture and failure of the epoxy adhesive and metal interface. For the Double Cantilever Beam (DCB), specimens were prepared and tested under quasi-static loading conditions. For this study, epoxy resin (FM73) was adhered with mild steel specimens with dimensions of $200 \mathrm{~mm} \times 15 \mathrm{~mm}$ x $10 \mathrm{~mm}$ and $200 \mathrm{~mm}$ x $15 \mathrm{~mm}$ × $7 \mathrm{~mm}$. Various parameters including varying adhesive thickness and initial pre-crack length were investigated. However, environmental conditions (testing temperature) and mild steel thickness were kept uniform in this study. The manufactured joins were tested under a range of both quasi-static conditions from mode I (opening mode) to mode II (Shear mode). For meaningful results, fracture and failure tests were performed using a simple and variable modeloading fixture [1].

After tests, fractured surfaces were investigated comprehensively under optical and scanning electron microscope (SEM). Figure 1 shows the fractured specimens under pure mode I, mixed mode and pure mode II loading conditions. Scanning electron microscope (SEM) images showed a fracture surface characterized by a fibrous structure which is most-likely of polyester mat present in the FM73 adhesive. It is evident from Figure 2(a) that epoxy has failed during opening mode (mode I) that exhibit fracture of uniform adhesive component of epoxy. Such mechanism is features as cohesive failure as adhesive itself is fractured under applied load. Moreover, Figure 2(a) also shows that failure is not related to adhesive failure where adhesive itself is peeled-off from the adherent surface. Figure 2(c) shows hackles that normally formed under Shear loading conditions (mode II). Such hackles were not observed in Figure 2(a). However, there are some degree of hackles in mixed-mode loading conditions too, as shown in Figure 2(b). Failure modes in the adhesively bonded joints are characterized according to the ASTM standard D5573-99 [2]. They are categorized as Adhesive failure (AF), Cohesive failure (CF), Thin-layer cohesive failure (TLCF), Fibre-tear failure (FTF), Light fibre-tear failure (LFTF), Stock-break failure and mixed failure.

It can be concluded from this study that the epoxy resin FM73 when bonded with mild steel exhibits cohesive failure in mode I (tensile loading), mixed-mode (mode I \& II) and pure mode II (Shear loading) conditions. There is no evidence of adhesive failure of FM73 when adhered to mild steel. Leffler et. al [3] investigated shear behavior of adhesive layers and reported cohesive failure in shear mode. It is reported that under mode II loading conditions, micro-cracks open in the direction of maximum normal stress at an angle of $45^{\circ}$. Once micro-cracks extends, adherend move in vertically direction that leads to final failure of the joint. Similar to Leffler et. al findings, failure mode was cohesive in the case of FM73/mild steel lap joint failure under mode II loading conditions. It has also been reported in literature 
that adhesive constraints swelling in the nominal pure shear loading could be a significant factor during failure of adhesively bonded structures [4].

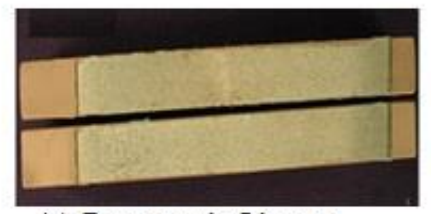

(a) Pure-mode I image

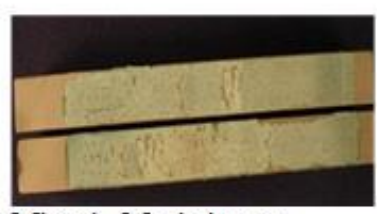

(b) Mixed- Mode image

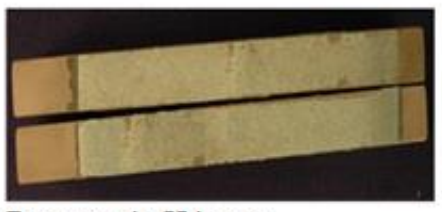

(c) Pure-mode II image

Figure 1. Failure surfaces observed visually under different mode conditions

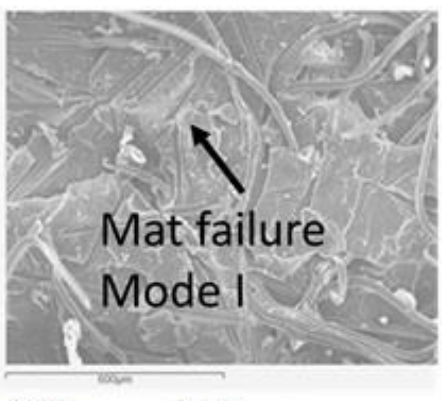

(a) Pure-mode I image

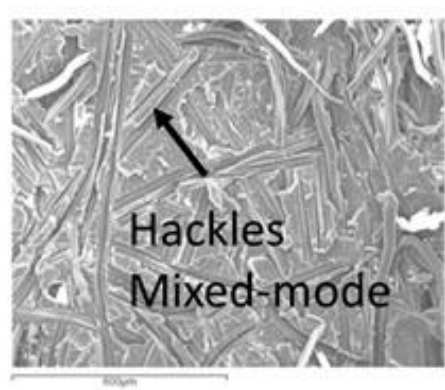

(b) Mixed-Mode image

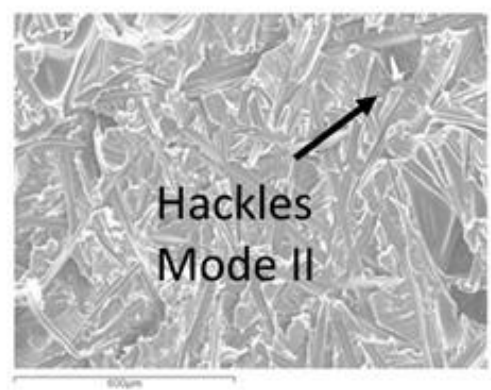

(c) Pure-mode II image

Figure 2. Different mode conditions images taken on Hitachi S-3200N SEM in MSSU

\section{References}

[1] H.T. Hafiz, M.M. Wahab, A.D. Crocombe, and P.A. Smith, "Mixed-mode fracture of adhesively bonded metallic joints under quasi-static loading”, Engineering Fracture Mechanics, Vol. 77, 2010, pp. 3434-3445.

[2] ASTM Standard D5573-99, "Standard practice for classifying failure modes in fibre-reinforced-plastic (FRP) joints" Annual Book of ASTM standards, Vol. 15.03, ASTM, 2007, USA

[3] K. Leffler, K. S. Alfredsson, U. Stigh, "Shear behavior of Adhesive layers", Int. Journal of Solids and Structures", Vol. 44, 2007, pp. $530-545$.

[4] U. Stigh and A. Biel, "Shear properties of an adhesive layer exposed to a compressive load" Procedia Materials Science 3, 2014, pp. 1626 - 1631. 